\title{
A Rapid Separation and Highly Determination of Paraben Species by Ultra-Performance Liquid Chromatography -Electrochemical Detection
}

\author{
Maneenuch Chuto $^{1}$, Sudkate Chaiyo ${ }^{1}$, Weena Siangproh ${ }^{2 *}$, Orawon Chailapakul ${ }^{1,3,4^{*}}$ \\ ${ }^{1}$ Department of Chemistry, Faculty of Science, Chulalongkorn University, Bangkok, Thailand; ${ }^{2}$ Department of Chemistry, Faculty of \\ Science, Srinakharinwirot University, Bangkok, Thailand; ${ }^{3}$ Center of Excellence for Petroleum, Petrochemicals and Advanced Mate- \\ rials, Chulalongkorn University, Bangkok, Thailand; ${ }^{4}$ Electrochemistry and Optical Spectroscopy Research Unit, Department of \\ Chemistry, Faculty of Science, Chulalongkorn University, Bangkok, Thailand. \\ Email: ${ }^{*}$ corawon@chula.ac.th, ${ }^{*}$ weenasi@hotmail.com
}

Received June $25^{\text {th }}, 2013$; revised July $30^{\text {th }}, 2013$; accepted August $8^{\text {th }}, 2013$

Copyright (C) 2013 Maneenuch Chuto et al. This is an open access article distributed under the Creative Commons Attribution License, which permits unrestricted use, distribution, and reproduction in any medium, provided the original work is properly cited.

\begin{abstract}
In this study, a new technique was developed using rapid ultra-performance liquid chromatography (UPLC)-based separation coupled with electrochemical detection by a boron-doped diamond (BDD) electrode for the detection and quantification of three commonly used parabens (methylparaben (MP), ethylparaben (EP) and propylparaben (PP)). We aimed to reduce the analysis time by using UPLC coupled with a short reverse phase C 18 monolithic column $(25 \mathrm{~mm} \times 4.6$ $\mathrm{mm}$ ). Operating the monolithic column at low back-pressure resulted in high flow rates. A mobile phaseconsisting of a 25:75 (v/v) ratio of acetonitrile: $0.05 \mathrm{M}$ phosphate buffer $\left(\mathrm{pH}\right.$ 5) at a flow rate of $2.5 \mathrm{~mL} \cdot \mathrm{min}^{-1}$ was used to perform the separation. The amperometric detection with the BDD electrode was found to be optimal and reliably reproducible at a detection potential of $1.5 \mathrm{~V}$ vs. $\mathrm{Ag} / \mathrm{AgCl}$. Under these conditions, the separation of the three targetanalytes (MP, EP and $\mathrm{PP})$ was achieved in 2 min and was linear within a sample concentration range of 0.1 to $50.0 \mathrm{mg} \cdot \mathrm{L}^{-1}\left(\mathrm{r}^{2}\right.$ values of $0.9970,0.9994$ and 0.9994 for MP, EP and PP, respectively). This method was successfully applied to determine the concentrations of each parabeninsix real samples with therecoveries ranging from of $80.3 \%-98.9 \%$ for all three parabensfrom samples spiked at 12,22 and $32 \mathrm{mg} \cdot \mathrm{L}^{-1}$. Therefore, the proposed method can be used as an alternative rapid and selective method for the determination of paraben levels in real samples.
\end{abstract}

Keywords: Parabens; Ultra-Performance Liquid Chromatography; Boron-Doped Diamond Electrode

\section{Introduction}

Parabens (4-hydroxybenzoic acid esters) are synthetic chemical preservatives used in a wide range of cosmetic, food and pharmaceutical products because they are broad spectrumantimicrobial and antifungal agents with a low toxicity to humans, have a good in situstability and are non-volatile [1]. The key to the bioactivities of parabens is their inhibition of membrane transport and mitochondrial function processes [2]. The antimicrobial activities of the different parabensappear to increase with increasing chain length, as length are accompanied with a concomitant reduction in water solubility [3]. In this work, the separation and quantification of three commonly used parabens, methylparaben (MP), ethylparaben (EP) and propylparaben (PP) (Figure 1), were proposed.

${ }^{*}$ Corresponding authors.
These three parabens were selected because they are the most frequently use din cosmetic products (e.g., creams, skin lotions or gels). Moreover, MP and PP are often used together due to their synergistic effects [3], requiring the ability to separate and quantify them from<smiles>COC(=O)c1ccc(O)cc1</smiles><smiles>CCOC(=O)c1ccc(O)cc1</smiles><smiles>CCCOC(=O)c1ccc(O)cc1</smiles>

Methylparaben (MP) Ethylparaben (EP) Propylparaben (PP)

Figure 1. Chemical structure of the three paraben analytes, in order (left to right) of elution from the reverse phase $\mathrm{C}$ 18 column. 
mixed sources. The European Economic Community (EEC) permits the use of parabens in cosmetics with a maximum total paraben concentration of $0.8 \%(\mathrm{w} / \mathrm{w})$ and $0.4 \%(\mathrm{w} / \mathrm{w})$ for any single paraben [4]. Likewise, the maximum concentration for parabens in foods is set at $0.1 \%(\mathrm{w} / \mathrm{w})$ and in pharmaceuticals at $1 \%(\mathrm{w} / \mathrm{w})[5,6]$. Based on several estimates, the total average paraben exposure for humans is $76 \mathrm{mg} \cdot \mathrm{day}^{-1}$ or $1.3 \mathrm{mg}$ (kg body weight $)^{-1} \cdot$ day $^{-1}$ which is derived from estimated exposure (intake) levels from cosmetics and personal products (50 $\mathrm{mg} \cdot$ day $\left.^{-1}\right)$, drugs $\left(25 \mathrm{mg} \cdot\right.$ day $\left.^{-1}\right)$ and food $\left(1 \mathrm{mg} \cdot\right.$ day $\left.^{-1}\right)$ [7]. Normally, parabens have a low toxicity because of their rapid in vivo hydrolysis. However, recently, there are an increasing number of reports on the weak estrogenic activity of parabensand reports that parabens can bind to estrogen receptors, which could potentially mediate some undesirable intermediate effects [8-11]. Furthermore, the detection of some parabens in both human breast tissue and human milk has been reported $[12,13]$. Hence, it is important to develop a reliable but quick and high-throughput method for the determination of parabens in real samples that retains sensitivity for low levels of detection. This technique would also require a broad enough linear detection range to logistically allow quantification of these parabens.

Several analytical methods for the detection and quantification of parabens have already been developed. Chromatographic methods are widely used, especially highperformance liquid chromatography (HPLC) [14-18] and gas chromatography (GC) $[13,19-22]$. Use of flow injecttion methods has also been reported [23,24]. These techniques are coupled with standard detection methods, most often ultraviolet (UV) detection [14-18], but chemiluminescent (CL) $[23,24]$ and mass spectrometric (MS) detection $[13,14,19,21,22]$ have also been reported. Capillary electrophoresis $[1,25]$ has also been reported. However, all of these methods are time-consuming, and some require that the samples are concentrated prior to the experiment. In addition, UV detection has a high limit of detection (LOD), CL detections are often unreliable due to inconsistencies in chemiluminescent generation and MS detection requires a high cost for the equipment and skilled operating labor.

In the last few years ultra-performance liquid chromatography (UPLC) has emerged [26-29]. UPLC offers several advantages for separation, such as using a smaller particle column and/or higher flow rates for increased speed. UPLC can operate at a much higher pressure of 1000 bar $(15,000 \mathrm{psi})$, which reduces the analysis time and thus allows for a higher sample throughput.

In addition, the use of a short monolithic columns has also been reported [15,30], based on the new sol-gel technology. The monolith particles consist of a high den- sity of macropores, so monolithic columns have a much higher porosity (approximately 15\%) than conventional particulate columns. As a consequence, the resulting column back-pressure is much lower, allowing operation at higher flow rates [31,32]. Moreover, the mesopores structure provides a very large active surface area for high efficiency separations. The reduced length and characteristics of the monolithic column are the important keys. The length of the column has been minimized, resulting in a reduced distance to transfer the analytes in the column.

Electrochemical detection (ECD) is an alternative method used here for the determination of parabens. A few electrochemical methods have already been reported that have the advantages of good sensitivity, low cost and simplicity [33,34]. In the past, a glassy carbon working electrode was used for the determination of parabens at low levels $\left(\mu \mathrm{g} \cdot \mathrm{mL}^{-1}\right)$ [34]. However, in this work, a boron-doped diamond (BDD) working electrode was evaluated. Compared with ordinary electrodes, BDD electrodes present many benefits, such as the wide potential window (up to $3 \mathrm{~V}$ ), very low and stable background current, longterm response stability and absence of fouling [35].

Thus, the purpose of this research was to develop a rapid, highly sensitive and accurate UPLC method coupled with electrochemical detection using a BDD electrode for the simultaneous determination of three commonly used parabens, MP, EP and PP, in real food, cosmetic and personal care product samples.

\section{Materials and Methods}

\subsection{Reagents and Solutions}

Methylparaben, Ethylparaben and Propylparaben were obtained from Sigma-Aldrich (Steinheim, Germany). Acetonitrile (HPLC-grade), methanol, ortho-phosphoric acid (85\%) and di-sodium hydrogen phosphate dehydrate were obtained from Merck (Darmstadt, Germany). Potassium dihydrogen phosphate was acquired from BDH laboratory supplies (VWR International Ltd., England). Water purification conducted using a Millipore Milli-Q purification system $\left(R \geq 18.2 \mathrm{M} \cdot \Omega \cdot \mathrm{cm}^{-1}\right)$ was used throughout.

A stock standard solution of each of the three parabens $(1000 \mu \mathrm{g} / \mathrm{mL})$ was prepared by dissolving $10 \mathrm{mg}$ of each paraben in $10 \mathrm{~mL}$ of a 1:1 (v/v) ratio acetonitrile: Milli-Q water in a volumetric flask. The solutions were then placed in an amber bottle and stored at $4^{\circ} \mathrm{C}$. The working solutions were prepared by suitable dilution of the stock standard solutions in the same solvent.

\subsection{Cyclic Voltammetry}

Electrochemical measurements were obtained using a $\mathrm{CH}$ Instrument potentiostat with a standard three elec- 
trode configuration including a BDD working electrode, a platinum counter electrode and an $\mathrm{Ag} / \mathrm{AgCl}$ reference electrode in $3 \mathrm{ml}$ of $0.05 \mathrm{M}$ phosphate buffer ( $\mathrm{pH} 5.0$ ), initially evaluated at various $\mathrm{pH}$ values between 4.0 and 8.0 and subsequently at the optimal $\mathrm{pH} 5.0$, in a volume of $3 \mathrm{~mL}$.

\subsection{UPLC Experiment and Apparatus}

UPLC was performed using a Shimadzu LC-20ADXR UFLC equipped with high-pressure binary pumps and a Chromolith ${ }^{\circledR}$ Flash RP-18 endcapped column $(25 \mathrm{~mm} \times$ $4.6 \mathrm{~mm}$ ) from Merck (Darmstadt, Germany). An electrochemical detector consisted of a $\mathrm{CH}$ Instrument potentiostat and a BDD electrode as the amperometric detector in a thin layer flow cell (GL Sciences, Inc.). The UPLCECD system utilized 25:75 (v/v) ratio acetonitrile: 0.05 $\mathrm{M}$ phosphate buffer ( $\mathrm{pH}$ 5) as the mobile phase with an applied potential of $1.5 \mathrm{~V}$ vs. $\mathrm{Ag} / \mathrm{AgCl}$ and a flow rate of $2.5 \mathrm{~mL} \cdot \mathrm{min}^{-1}$. The experiments were performed at $25^{\circ} \mathrm{C}$.

\subsection{Electrochemical Measurement}

The thin-layer flow cell consisted of three electrodes: a $\mathrm{BDD}$ working electrode, an $\mathrm{Ag} / \mathrm{AgCl}$ reference electrode (Bioanalytical System, Japan) and a stainless steel tube counter electrode. The geometric area of the BDD electrode in the flow cell was estimated to be $0.42 \mathrm{~cm}^{2}$ with a $1 \mathrm{~mm}$ thick silicon rubber gasket as a spacer. An electrochemical analyzer (CHI1232a, CH-instrument, USA) was used for amperometric control and signal processing.

\subsection{Sample Preparation}

The six real samples that were analyzed are presented in Table 1. Samples A, D and E were extracted with 2.5 $\mathrm{mL}$ of methanol. The mixture was extracted by sonication for $15 \mathrm{~min}$ in an ultrasonic bath (ESP chemicals, Inc., MA, USA), whereas samples B, C and F were extracted in methanol by vortexing for $3 \mathrm{~min}$ in a vortex mixer (Mixer Uzusio LMS. Co. Ltd., Japan). All the mixtures were then clarified by centrifugation (Cole Parmer, USA)

Table 1. The real product samples used in this research.

\begin{tabular}{cccc}
\hline Product type & Product sample & Code & $\begin{array}{c}\text { Extraction } \\
\text { (sample: methanol) }\end{array}$ \\
\hline Food & Soft drink & A & $1 \mathrm{~mL}: 2.5 \mathrm{~mL}$ \\
Personal care & Jelly & B & $300 \mathrm{mg}: 1.5 \mathrm{~mL}$ \\
Coothpaste & C & $300 \mathrm{mg}: 1.5 \mathrm{~mL}$ \\
& $\begin{array}{c}\text { Mouthwash } \\
\text { Lotion }\end{array}$ & D & $1 \mathrm{~mL}: 2.5 \mathrm{~mL}$ \\
& $\begin{array}{c}\text { Blemish Balm } \\
\text { powder } \\
\text { (BB powder) }\end{array}$ & F & $1 \mathrm{~mL}: 2.5 \mathrm{~mL}$ \\
& & & $50 \mathrm{mg}: 1.5 \mathrm{~mL}$ \\
\hline
\end{tabular}

at $6000 \mathrm{rpm}$ and the supernatant was harvested for preparation of the appropriate dilutions such that the concentration of parabens in the final test solution was within the linear dynamic range (found to be $0.1-50 \mu \mathrm{g} \cdot \mathrm{mL}^{-1}$ ). Samples were filtered through a $0.22 \mu \mathrm{m}$ nylon membrane filter before injection into the UPLC-ECD system.

\subsection{Data Analysis}

Standards and samples were analyzed, and peak areas were integrated. Standard curves were obtained by plotting the net peak area as a function of the analyte concentration and fitting the data to a linear equation. To compare the two measurement systems, which are supposed to be equivalent, the results were tested using the paired t-test.

\section{Results and Discussion}

\subsection{Cyclic Voltammetry}

The electrooxidation behavior of methylparaben (MP), ethylparaben (EP) and propylparaben (PP) were first investigated by cyclic voltammetry at the BDD electrode. Preliminary trials established that a $0.05 \mathrm{~mol} \cdot \mathrm{L}^{-1}$ phosphate buffer was an optimal supporting electrolyte for paraben detection because it provided the lowest background current (data not shown). The effect of different $\mathrm{pH}$ values $(\mathrm{pH} 4-8)$ of the $0.05 \mathrm{~mol} \cdot \mathrm{L}^{-1}$ phosphate buffer on the electrooxidation behavior of MP, EP and PP $\left(50 \mathrm{mg} \cdot \mathrm{L}^{-1}\right)$ were then investigated by cyclic voltammetry at the BDD electrode. Figure 2 shows the relationships between the current obtained from three parabens and the buffer $\mathrm{pH}$.

For all three parabens, the best operating current was obtained at $\mathrm{pH} 5$. An equivalent or greater current was observed at $\mathrm{pH} 8$, but high $\mathrm{pH}$ values will dissolve the

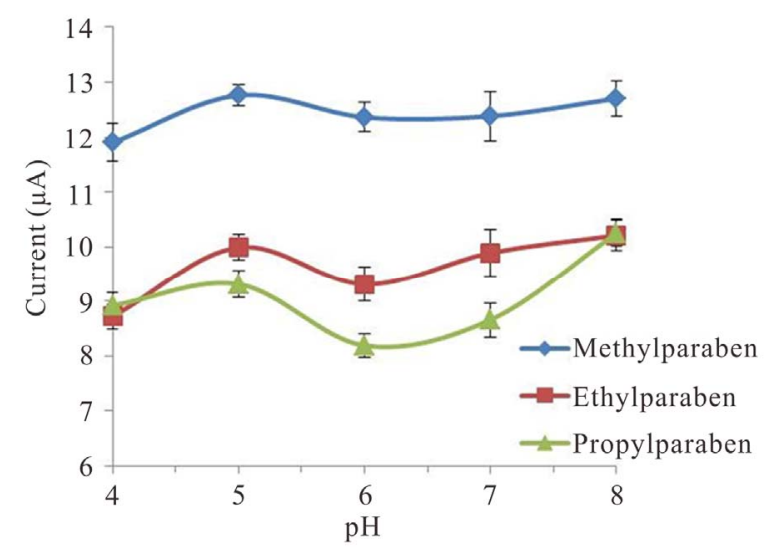

Figure 2. Effect of the $\mathrm{pH}$ on the obtained peak current of each paraben at $50 \mathrm{mg} \cdot \mathrm{L}^{-1}$ by cyclic voltammetry. Data are shown as the mean \pm 1 SD and are derived from 3 independent repeats. Means with a different lowercase letter are significantly different ( $\mathrm{P}<0.05$; Duncan's MMT). 
silica and cause an increased void volume in the column. Therefore, $0.05 \mathrm{~mol} \cdot \mathrm{L}^{-1}$ phosphate buffer at $\mathrm{pH} 5.0$ was selected for all subsequent work.

\subsection{UPLC Separation}

The separation of MP, EP and PP (each at $10 \mathrm{mg} \cdot \mathrm{L}^{-1}$ ) was performed using the $\mathrm{C} 18$ short monolithic column in the isocratic mode. The acetonitrile: $0.05 \mathrm{~mol} \cdot \mathrm{L}^{-1}$ phosphate buffer ( $\mathrm{pH} 5$ ) was investigated from a 25:75 to 40:60 (v/v) ratios at a flow rate of $1.5 \mathrm{~mL} \cdot \mathrm{min}^{-1}$. The optimal $(\mathrm{v} / \mathrm{v})$ ratio of acetonitrile: $0.05 \mathrm{~mol} \cdot \mathrm{L}^{-1}$ phosphate buffer pH 5 was determined to be 25:75 (Figure 3(a)). As the acetonitrile concentration decreased, the resolution of the three parabens increased. However, this was at the cost of an almost three-fold longer elution time. Nevertheless, the monolithic column has a total porosity greater than $80 \%$, so a higher flow rate could be achieved without a loss of resolution.

Thus to confirm this, an increased flow rate of 2.5 $\mathrm{mL} \cdot \mathrm{min}^{-1}$ was evaluated, and it yielded a good separation of the three parabens within a much shorter elution time of 2 min (Figure 3(b)). The retention time of the three parabens was $0.6,0.9$ and $1.8 \mathrm{~min}$ for MP, EP and $\mathrm{PP}$, respectively, and this time was dependent on the polarity of the species, as expected.

\subsubsection{UPLC Column Type}

A comparative study on the column performance between a microparticle C 18 packed column (Shim-pack XR-ODS II) and two reverse C 18 monolithic columns (Chromolith ${ }^{\circledR}$ Performance and Chromolith ${ }^{\circledR}$ Flash) was performed. The retention times for the three parabens by UPLC-ECD varied significantly between the three different columns (Table 2), with the C 18 monolithic column under these conditions having by far the fastest analytical speed. The shim-pack XR-ODS II C 18 packing column, which generated the highest back-pressure, had a longer elution time than the short $\mathrm{C} 18$ monolithic column (Chromolith ${ }^{\circledR}$ Flash RP 18), whereas the extended monolith column had a longer time than the short column. Thus, the Chromolith ${ }^{\circledR}$ Flash RP-18 column,

Table 2. The elution times for the three parabens from three different columns used in the UPLC-ECD.

\begin{tabular}{ccccc}
\hline Analytical column & Flow rate & \multicolumn{3}{c}{ Elution time (min) } \\
\hline & $\left(\mathbf{m L} \cdot \mathbf{m i n}^{-\mathbf{1}}\right)$ & MP & EP & PP \\
\hline $\begin{array}{c}\text { Shim-pack XR-ODS II } \\
(100 \mathrm{~mm} \times 2.0 \mathrm{~mm} \text { i. d. })\end{array}$ & $0.6^{*}$ & 2.2 & 4.3 & 9.6 \\
$\begin{array}{c}\text { Chromolith } \\
(100 \mathrm{~mm} \times 4.6 \mathrm{~mm} \text { i. d. })\end{array}$ & 2.5 & 1.7 & 3.0 & 6.6 \\
$\begin{array}{c}\text { Chromolith } \\
(25 \mathrm{~mm} \times 4.6 \mathrm{~mm} \text { i. d. })\end{array}$ & 2.5 & 0.6 & 0.9 & 1.8 \\
\hline
\end{tabular}

*At the maximum pressure of the column.

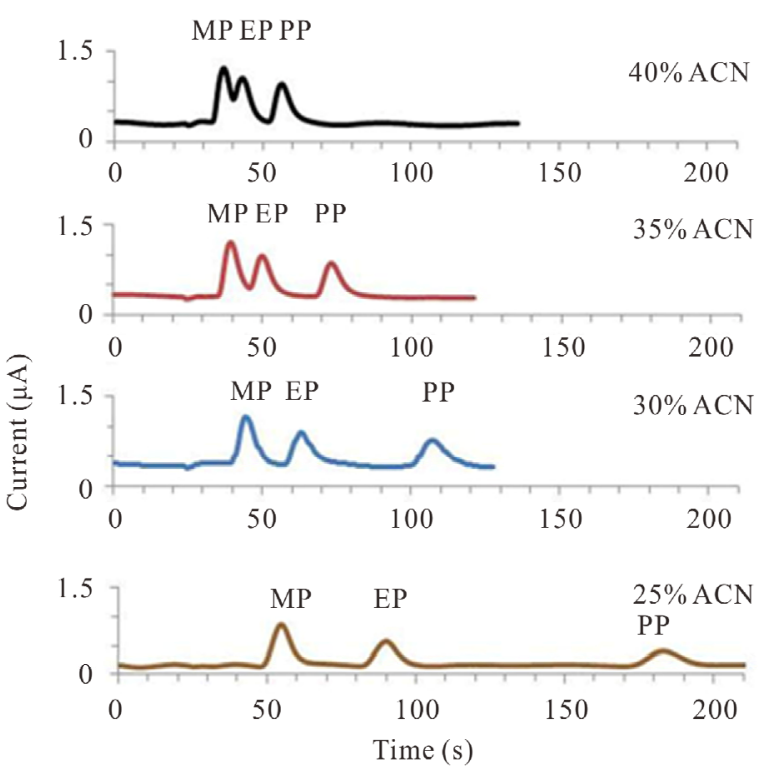

(a)

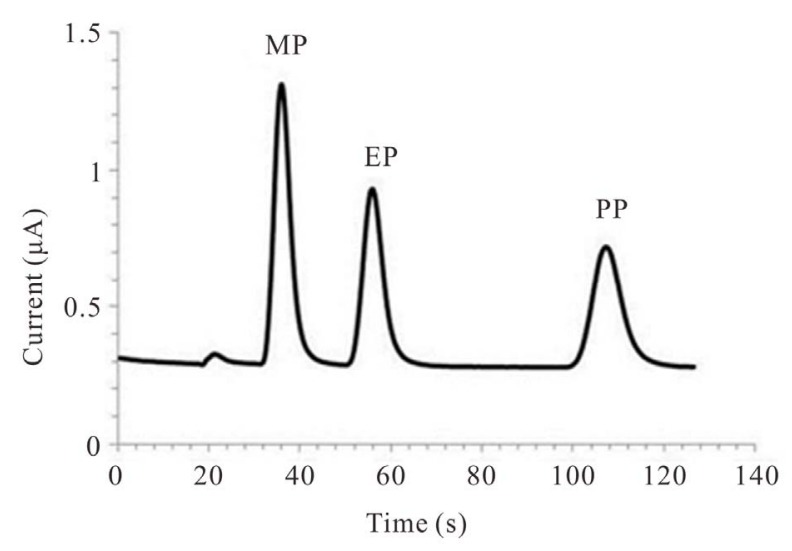

(b)

Figure 3. UPLC-ECD chromatogram of the three parabens at $10 \mathrm{ppm}$ each and separated on a $\mathrm{C} 18$ monolithic column (a) at a flow rate of $1.5 \mathrm{~mL} \cdot \mathrm{min}^{-1}$ with different $(\mathrm{v} / \mathrm{v})$ ratios of acetonitrile (ACN): $0.05 \mathrm{M}$ phosphate buffer ( $\mathrm{pH}$ 5.0) as the mobile phase; and (b) with a $1: 3(\mathrm{v} / \mathrm{v})$ ratio of acetonitrile: $0.05 \mathrm{M}$ phosphate buffer (pH 5.0) and a flow rate of $2.5 \mathrm{~mL} \cdot \mathrm{min}^{-1}$. In all cases the detection potential was $1.5 \mathrm{~V}$ vs. Ag/AgCl using a BDD electrode. Chromatographs shown are representative of those seen in 3 independent repeats.

which is very short and perfect for ultra-fast analysis, was selected as the most suitable column when speed of the analysis is an important factor.

\subsubsection{ECD Potential}

The effect of varying detection potential (ranging from 1.3 to $1.6 \mathrm{~V}$ vs. $\mathrm{Ag} / \mathrm{AgCl}$ ) on the peak current obtained with the BDD electrode for the three parabens was also investigated. The oxidation current of the parabens was 
found to be significantly affected by the detection potentials. The i-E curve for the three parabens, shown in Figure 4, demonstrates an increase in current as the applied potential increased up to $1.5 \mathrm{~V}$, followed by a decrease in current at $1.6 \mathrm{~V}$ vs. $\mathrm{Ag} / \mathrm{AgCl}$ due to the high background current when operating at higher potential. Thus, a detection potential of $1.5 \mathrm{~V}$ vs. $\mathrm{Ag} / \mathrm{AgCl}$ was selected as the optimal potential for the amperometric detection of these three parabens.

\subsection{Analytical Performance}

The calibration of the obtained chromatograph peak areas against the respective paraben concentrations were plotted (data not shown), and a linear relationship was determined for all of the three parabens within the range of 0.1 to $50 \mathrm{mg} \cdot \mathrm{L}^{-1}$, with coefficients of determination (r 2) $\geq 0.997$ for the three parabens (Table 3). The calculated LOD and LOQ values from this data, using $3 \mathrm{~S} / \mathrm{N}$ to 10 $\mathrm{S} / \mathrm{N}$, respectively, were the same for all three parabens (Table 3), and the values compare well with those that have previously been reported using different methods [33].

\subsection{Application to Real Samples}

The proposed method was applied to six different samples, derived from food, personal care and cosmetic products (two each, see Table 1) that were purchased from local supermarkets. The chromatograms for the six real samples are presented in Figure 5, where it demonstrated that the matrix compounds do not interfere with the analytes. The peaks were identified by comparison with the three paraben standards, and the results are

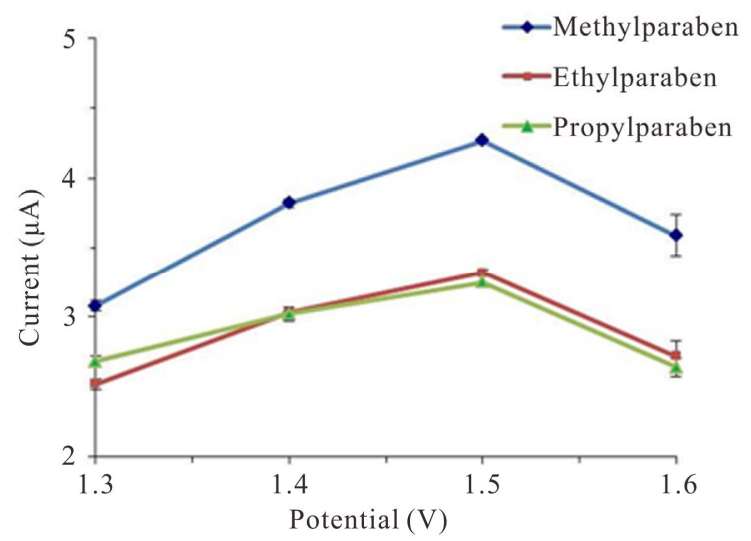

Figure 4. Effect of the detection potential on the peak current obtained from the BDD electrode with $10 \mathrm{mg} \cdot \mathrm{L}^{-1}$ of each indicated parabens in $0.05 \mathrm{M}$ phosphate buffer (pH 5.0) at a flow rate of $2.5 \mathrm{~mL} \cdot \mathrm{min}^{-1}$. Data are shown as the mean \pm 1 SD and are derived from 3 independent repeats. Means with a different lowercase letter are significantly different ( $\mathrm{P}<0.05$; Duncan's MMT).
Table 3. Linearity range, limit of detection (LOD) and limit of quantitation (LOQ) of the UPLC-ECD method for the three parabens.

\begin{tabular}{cccccc}
\hline Analytes & $\begin{array}{c}\text { Linearity } \\
\text { range } \\
\left(\mathbf{m g} \cdot \mathbf{L}^{-1}\right)\end{array}$ & $\begin{array}{c}\text { Slope } \\
(\mathbf{p e a k} \mathbf{a r e a}) \\
\left(\mathbf{u n i t s} / \mathbf{m g} \cdot \mathbf{L}^{-1}\right)\end{array}$ & $\mathbf{r}^{2}$ & $\begin{array}{c}\mathbf{L O D} \\
\left(\mathbf{m g} \cdot \mathbf{L}^{-1}\right)\end{array}$ & $\begin{array}{c}\mathbf{L O Q} \\
\left(\mathbf{m g} \cdot \mathbf{L}^{-1}\right)\end{array}$ \\
\hline MP & $0.1-50$ & 0.2912 & 0.9970 & 0.03 & 0.1 \\
EP & $0.1-50$ & 0.2530 & 0.9994 & 0.03 & 0.1 \\
PP & $0.1-50$ & 0.2479 & 0.9994 & 0.03 & 0.1 \\
\hline
\end{tabular}
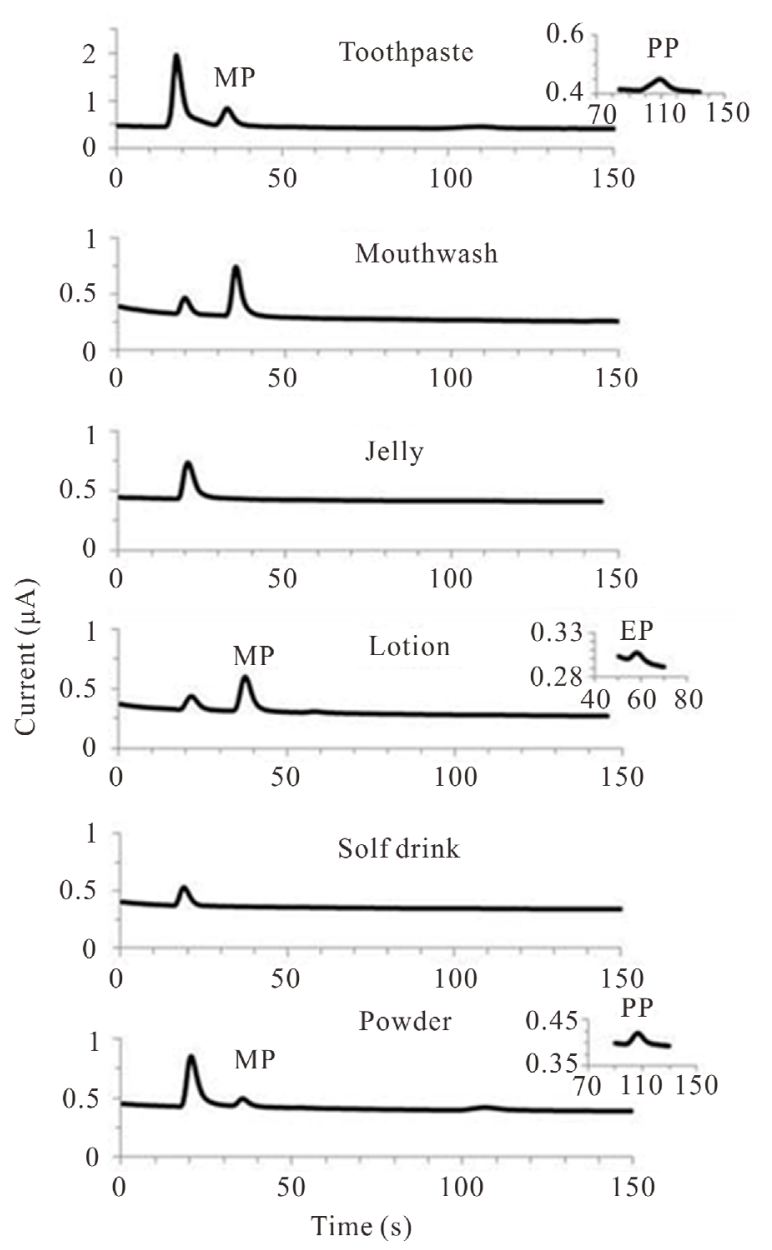

Figure 5. UPLC-ECD derived chromatograms of the three parabens in six real samples. Peaks labeled MP, EP and PP are methylparaben, ethylparaben and propylparaben, respectively, and were designated by comparison of retention times to known standards. Insets show a magnified scale. Chromatographs shown are representative of those seen in 3 independent repeats, and the samples are as per in Table 1.

summarized in Table 4, along with the analysis of the same samples by the standard UPLC-UV detection method, for comparison. 
Table 4. Determination of the parabens levels in six real samples.

\begin{tabular}{|c|c|c|c|c|c|c|}
\hline \multirow{2}{*}{ Samples $^{\mathrm{a}}$} & \multicolumn{2}{|c|}{ Methylparaben } & \multicolumn{2}{|c|}{ Ethylparaben } & \multicolumn{2}{|c|}{ Propylparaben } \\
\hline & $\begin{array}{c}\text { UPLC-ECD } \\
\left(\mathrm{mg} \cdot \mathrm{L}^{-1}\right)\end{array}$ & $\begin{array}{c}\text { UPLC-UV } \\
\left(\mathbf{m g} \cdot \mathbf{L}^{-1}\right)\end{array}$ & $\begin{array}{c}\text { UPLC-ECD } \\
\left(\mathrm{mg} \cdot \mathrm{L}^{-1}\right)\end{array}$ & $\begin{array}{c}\text { UPLC-UV } \\
\left(\mathbf{m g} \cdot \mathbf{L}^{-1}\right)\end{array}$ & $\begin{array}{c}\text { UPLC-ECD } \\
\left(\mathbf{m g} \cdot \mathbf{L}^{-1}\right)\end{array}$ & $\begin{array}{c}\text { UPLC-UV } \\
\left(\mathbf{m g} \cdot \mathbf{L}^{-1}\right)\end{array}$ \\
\hline Soft drink (A) & - & - & - & - & - & - \\
\hline Jelly (B) & - & - & - & - & - & - \\
\hline Toothpaste (C) & $240.0 \pm 0.5$ & $290.0 \pm 0.5$ & - & - & $130.0 \pm 0.2$ & $100.0 \pm 0.2$ \\
\hline Mouthwash (D) & $630.0 \pm 0.4$ & $700.0 \pm 0.2$ & - & - & - & - \\
\hline Lotion (E) & $437.0 \pm 0.3$ & $472.5 \pm 0.2$ & $35.0 \pm 0.0$ & $52.5 \pm 0.0$ & - & - \\
\hline BB Powder (F) & $360.0 \pm 0.0$ & $420.0 \pm 0.1$ & - & - & $480.0 \pm 0.0$ & $480.0 \pm 0.0$ \\
\hline $\mathrm{t}$ value (at $12 \mathrm{mg} \cdot \mathrm{L}^{-1}$ ) & \multicolumn{2}{|c|}{-0.7408} & \multicolumn{2}{|c|}{2.4752} & \multicolumn{2}{|c|}{1.9383} \\
\hline $\mathrm{t}$ value (at $22 \mathrm{mg} \cdot \mathrm{L}^{-1}$ ) & \multicolumn{2}{|c|}{-0.7882} & \multicolumn{2}{|c|}{0.8953} & \multicolumn{2}{|c|}{2.1581} \\
\hline $\mathrm{t}$ value (at $32 \mathrm{mg} \cdot \mathrm{L}^{-1}$ ) & \multicolumn{2}{|c|}{-0.5355} & \multicolumn{2}{|c|}{-0.4202} & \multicolumn{2}{|c|}{2.1222} \\
\hline$t$ critical & \multicolumn{6}{|c|}{2.5706} \\
\hline
\end{tabular}

${ }^{\mathrm{a}}$ Sample codes are as in Table 1, Data are shown as the mean $\pm 1 \mathrm{SD}$, and are derived from 3 independent repeats.

However, the actual paraben levels in the samples were unknown. For a direct comparison with the UPLCUV method, the results obtained using UPLC-ECD and standard UPLC-UV were compared by a paired-t-test for three samples that were spiked with different known paraben concentrations $\left(12,22\right.$ and $32 \mathrm{mg} \cdot \mathrm{L}^{-1}$ to represent a low, medium and high level, respectively). The critical t-value (2.5706) was significantly higher than the experimental $\mathrm{t}$-values between the two pairs of assays. Using the UPLC-ECD method, the t-values for MP, EP and PP were $-0.7408,2.4752$ and 1.9383, respectively, for a spiked sample at $12 \mathrm{mg} \cdot \mathrm{L}^{-1}$ For a spiked sample at $22 \mathrm{mg} \cdot \mathrm{L}^{-1}$, t-values were $-0.7882,0.8953$ and 2.1581 , respectively, and for a spiked sample at $32 \mathrm{mg} \cdot \mathrm{L}^{-1}, \mathrm{t}-$ values were $-0.5355,-0.4202$ and 2.1222 , respectively. There were no significant differences between the two assay methods at all three spiked concentrations. Thus, the results obtained from the developed method can be accepted.

The precision of the UPLC-ECD method was then validated by calculating the relative standard deviations (RSD) from triplicates using the same three paraben concentrations as above $\left(12.0,22.0\right.$ and $32.0 \mathrm{mg} \cdot \mathrm{L}^{-1}$, or low, medium and high). The precision and accuracy data for the three parabens in the six samples are summarized in Table 5. The inter-day precision levels were in the range of $0.3 \%-4.9 \%, 1.0 \%-4.8 \%$ and $1.9 \%-4.9 \%$ for $\mathrm{MB}$, $\mathrm{EB}$ and $\mathrm{PB}$, respectively. The intra-day precision levels were very similar, ranging from $0.4 \%-4.9 \%, 2.2 \%$ $4.8 \%$ and $0.7 \%-4.9 \%$ for $\mathrm{MB}, \mathrm{EB}$ and $\mathrm{PB}$, respectively. The inter-day recoveries were in the range of $80.3 \%$ -
$96.6 \%, 81.1 \%-94.4 \%$ and $83.2 \%-96.5 \%$ for $\mathrm{MB}, \mathrm{EB}$ and $\mathrm{PB}$, respectively, and the intra-day recovery levels were also similar at $80.3 \%-96.0 \%, 80.4 \%-96.5 \%$ and $81.6 \%$ - 98.9\% for MB, EB and PB, respectively. Thus, this method was demonstrated to be reproducible over time.

\section{Conclusion}

In this work, a method for the rapid analysis of three commonly used paraben preservatives (MP, EP and PP) by UPLC coupled with ECD using a BDD electrode was successfully developed. Particular attention was focused on the use of a monolithic column coupled with a UPLC instrument for fast separation that arose from an increased flow rate (reducing evaluation time) without a loss of resolution. In addition, the innovative ECD system using a BDD electrode, with an optimal potential of $1.5 \mathrm{~V}$ vs. $\mathrm{Ag} / \mathrm{AgCl}$, yielded a high degree of reproducibility, based on \% RSDs for the intra- and inter-assays below 5\%. Analysis time was 2 min or less. This method was applied to six real samples, two each of food, personal care and cosmetic products and was found to yield acceptably similar results as the standard UPLC-UV method for detection of the three test parabens. Both methods provided a high speed of separation, however, the proposed method improved the efficiency of these preservatives in terms of better sensitivity when compared to the standard method. In conclusion, UPLC-ECD using a BDD electrode was proved to be an attractive alternative method for detection of parabens in real samples. 
Table 5. The inter- and intra-precisions and recoveries of the three parabens from the UPLC-ECD method.

\begin{tabular}{|c|c|c|c|c|c|c|c|c|c|c|c|c|c|}
\hline \multirow{3}{*}{ Samples ${ }^{\mathrm{a}}$} & \multirow{3}{*}{$\begin{array}{c}\text { Spiked } \\
\text { level } \\
\left(\mathbf{m g} \cdot \mathbf{L}^{-1}\right)\end{array}$} & \multicolumn{6}{|c|}{ Intra-day } & \multicolumn{6}{|c|}{ Inter-day } \\
\hline & & \multicolumn{2}{|c|}{ Methylparaben } & \multicolumn{2}{|c|}{ Ethylparaben } & \multicolumn{2}{|c|}{ Propylparaben } & \multicolumn{2}{|c|}{ Methylparaben } & \multicolumn{2}{|c|}{ Ethylparaben } & \multicolumn{2}{|c|}{ Propylparaben } \\
\hline & & Recovery & RSD & Recovery & RSD & Recovery & RSD & Recovery & RSD & Recovery & RSD & Recovery & RSD \\
\hline \multirow{3}{*}{ Sample A } & 12 & $87.9 \pm 4.3$ & 4.7 & $86.6 \pm 4.1$ & 4.8 & $85.9 \pm 4.3$ & 4.3 & $82.7 \pm 2.3$ & 2.8 & $84.8 \pm 3.3$ & 3.9 & $85.1 \pm 4.1$ & 4.8 \\
\hline & 22 & $93.7 \pm 3.7$ & 4.0 & $94.2 \pm 2.2$ & 2.3 & $97.2 \pm 2.1$ & 2.1 & $86.1 \pm 4.1$ & 4.8 & $87.7 \pm 3.1$ & 3.6 & $88.3 \pm 3.5$ & 4.0 \\
\hline & 32 & $89.2 \pm 2.9$ & 3.3 & $92.8 \pm 2.4$ & 2.6 & $95.5 \pm 2.1$ & 2.2 & $83.2 \pm 3.7$ & 4.4 & $87.2 \pm 4.1$ & 4.7 & $89.9 \pm 4.4$ & 4.9 \\
\hline \multirow{3}{*}{ Sample B } & 12 & $80.3 \pm 0.4$ & 0.4 & $82.2 \pm 2.2$ & 2.7 & $91.1 \pm 2.8$ & 3.1 & $80.3 \pm 0.2$ & 0.3 & $81.1 \pm 0.8$ & 1.0 & $89.6 \pm 1.7$ & 1.9 \\
\hline & 22 & $81.9 \pm 2.8$ & 3.4 & $86.2 \pm 2.2$ & 2.5 & $97.5 \pm 0.8$ & 0.9 & $82.1 \pm 2.7$ & 3.3 & $84.6 \pm 3.9$ & 4.6 & $94.2 \pm 4.5$ & 4.8 \\
\hline & 32 & $81.6 \pm 0.4$ & 0.5 & $83.8 \pm 1.9$ & 2.2 & $96.7 \pm 0.7$ & 0.7 & $81.3 \pm 0.4$ & 0.5 & $84.4 \pm 3.2$ & 3.8 & $92.7 \pm 4.6$ & 4.9 \\
\hline \multirow{3}{*}{ Sample C } & 12 & $80.7 \pm 0.5$ & 0.6 & $80.4 \pm 0.2$ & 0.3 & $84.4 \pm 1.6$ & 2.0 & $82.2 \pm 2.4$ & 3.0 & $82.7 \pm 3.5$ & 4.2 & $83.2 \pm 1.8$ & 2.2 \\
\hline & 22 & $84.5 \pm 3.2$ & 3.8 & $81.9 \pm 3.0$ & 3.6 & $84.0 \pm 2.5$ & 3.0 & $94.4 \pm 3.8$ & 4.0 & $89.1 \pm 3.8$ & 4.2 & $92.6 \pm 2.1$ & 2.3 \\
\hline & 32 & $82.5 \pm 2.8$ & 3.4 & $80.2 \pm 0.1$ & 0.2 & $85.1 \pm 3.2$ & 3.8 & $84.5 \pm 4.1$ & 4.9 & $84.8 \pm 4.1$ & 4.8 & $89.8 \pm 2.3$ & 2.5 \\
\hline \multirow{3}{*}{ Sample D } & 12 & $96.0 \pm 1.7$ & 1.7 & $80.8 \pm 1.3$ & 1.3 & $81.6 \pm 0.6$ & 0.8 & $96.6 \pm 1.7$ & 1.7 & $81.1 \pm 0.8$ & 1.0 & $83.8 \pm 2.8$ & 3.3 \\
\hline & 22 & $90.8 \pm 4.1$ & 4.5 & $86.2 \pm 3.2$ & 3.7 & $88.5 \pm 4.4$ & 4.9 & $89.5 \pm 2.1$ & 2.4 & $83.8 \pm 2.1$ & 2.5 & $84.5 \pm 3.3$ & 3.9 \\
\hline & 32 & $81.8 \pm 1.3$ & 1.6 & $81.9 \pm 1.4$ & 1.7 & $87.8 \pm 1.6$ & 1.8 & $82.2 \pm 0.7$ & 0.9 & $82.0 \pm 1.5$ & 1.8 & $83.3 \pm 3.6$ & 4.3 \\
\hline \multirow{3}{*}{ Sample E } & 12 & $86.2 \pm 0.6$ & 0.7 & $94.5 \pm 1.1$ & 1.2 & $98.9 \pm 0.9$ & 0.9 & $85.9 \pm 1.2$ & 1.4 & $90.8 \pm 4.3$ & 4.8 & $93.2 \pm 3.6$ & 3.9 \\
\hline & 22 & $90.4 \pm 3.9$ & 4.3 & $96.5 \pm 1.7$ & 1.8 & $97.9 \pm 1.4$ & 1.5 & $89.0 \pm 4.0$ & 4.5 & $94.4 \pm 3.4$ & 3.6 & $96.5 \pm 3.1$ & 3.2 \\
\hline & 32 & $80.7 \pm 0.2$ & 0.3 & $83.4 \pm 2.2$ & 2.6 & $96.7 \pm 1.3$ & 1.3 & $82.1 \pm 1.6$ & 2.0 & $82.0 \pm 1.8$ & 2.2 & $94.4 \pm 2.5$ & 2.7 \\
\hline \multirow{3}{*}{ Sample F } & 12 & $98.8 \pm 1.7$ & 1.7 & $95.5 \pm 2.1$ & 2.2 & $93.1 \pm 4.2$ & 4.5 & $93.2 \pm 4.6$ & 4.9 & $91.1 \pm 4.2$ & 4.7 & $91.5 \pm 4.1$ & 4.4 \\
\hline & 22 & $95.3 \pm 3.6$ & 3.8 & $89.7 \pm 4.0$ & 4.5 & $84.2 \pm 3.3$ & 3.9 & $93.0 \pm 4.4$ & 4.7 & $94.0 \pm 2.4$ & 2.6 & $90.8 \pm 3.7$ & 4.1 \\
\hline & 32 & $94.7 \pm 4.6$ & 4.9 & $95.2 \pm 3.6$ & 3.8 & $94.7 \pm 4.5$ & 4.8 & $89.9 \pm 4.1$ & 4.6 & $94.1 \pm 4.5$ & 4.7 & $93.2 \pm 2.6$ & 2.8 \\
\hline
\end{tabular}

${ }^{\mathrm{a}}$ Sample codes are as in Table 1, Data are shown as the mean $\pm 1 \mathrm{SD}$, and are derived from 3 independent repeats.

\section{Acknowledgements}

This research was financially supported by the Innovation for the improvement of food safety and food quality for new world economy project, National Research Council of Thailand (NRCT) under the project High throughput Screening/Analysis: Tool for Drug Discovery Diagnosis and Health Safety and the $90 \mathrm{TH}$ Anniversary of Chulalongkorn University Fund. This work (AM1009I) was supported by the Higher Education Research Promotion and National Research University Project of Thailand, Office of the Higher Education Commission and the Ratchadaphisaksomphot Endowment Fund. The authors also would like to thanks the Thai Government Stimulus Package 2 (TKK 2555), under the Project for Establishment of Comprehensive Center for Innovative Food, Health Products and Agriculture (PERFECTA).

\section{REFERENCES}

[1] Q. Chu. J. Wang, D. Zhang and J. Ye, "Sensitive Determination of Parabens in Soy Sauces by Capillary Zone Electrophoresis with Amperometric Detection," European Food Research and Technology, Vol. 231, No. 6, 2010, pp. 891-897. http://dx.doi.org/10.1007/s00217-010-1343-2

[2] M. G. Soni, I. G. Carabin and G. A. Burdock, "Safety Assessment of Esters of p-Hydroxybenzoic Acid (Parabens)," Food and Chemical Toxicology, Vol. 43, No. 7, 2005, pp. 985-1015.

\section{http://dx.doi.org/10.1016/j.fct.2005.01.020}

[3] B. Saad, M. F. Bari, M. I. Saleh, K. Ahmad and M. K. M. Talib, "Simultaneous Determination of Preservatives (Benzoic Acid, Sorbic Acid, Methylparaben and Propylparaben) in Foodstuffs Using High-Performance Liquid Chromatography," Journal of Chromatography A, Vol. 1073, No. 1-2, 2005, pp. 393-397. http://dx.doi.org/10.1016/j.chroma.2004.10.105

[4] I. Marquez-Sillero, E. Aguilera-Herrador, S. Cardenas and M. Valcarcel, "Determination of Parabens in Cosmetic Products Using Multi-Walled Carbon Nanotubes as Solid Phase Extraction Sorbent and Corona-Charged Aerosol Detection System," Journal of Chromatography A, Vol. 1217, No. 1, 2010, pp. 1-6. http://dx.doi.org/10.1016/j.chroma.2009.11.005

[5] D. Casoni, I. A. Tuhutiu and C. Sarbu, "Simultaneouse Determination of Parabens in Pharmaceutical Preparations Using High-Performance Thin-Layer Chromatography and Image Analysis," Journal of Liquid Chromatography \& Related Technologies, Vol. 34, No. 10-11, 2011, pp. 805-816. http://dx.doi.org/10.1080/10826076.2011.571141

[6] M. G. Soni, G. A. Burdock, S. L. Taylor and N. A. Greenberg, "Safety Assessment of Propyl Paraben: A Review of the Published Literature," Food and Chemical Toxicology, Vol. 39, No. 6, 2001, pp. 513-532. http://dx.doi.org/10.1016/S0278-6915(00)00162-9

[7] Q. Zhang, M. Lian, L. Liu and H. Cui, "High-Performance Liquid Chromatographic Assay of Parabens in WashOff Cosmetic Products and Foods Using Chemiluminescence Detection," Analytica Chimica Acta, Vol. 537, No. 
1-2, 2005, pp. 31-39.

http://dx.doi.org/10.1016/j.aca.2005.01.027

[8] J. R. Byford, L. E. Shaw, M. G. B. Drew, G. S. Pope, M. J. Sauer and P. D. Darbre, "Oestrogenic Activity of Parabens in MCF7 Human Breast Cancer Cells," Journal of Steroid Biochemistry \& Molecular Biology, Vol. 80, No. 1, 2002, pp. 49-60. http://dx.doi.org/10.1016/S0960-0760(01)00174-1

[9] P. D. Darbre, A. Aljarrah, W. R. Miller, N. G. Coldham, M. J. Sauer and G. S. Pope, "Concentrations of Parabens in Human Breast Tumours," Journal of Applied Toxicology, Vol. 24, No. 1, 2004, pp. 5-13. http://dx.doi.org/10.1002/jat.958

[10] E. J. Routledge, J. Parker, J. Odum, J. Ashby and J. P. Sumpter, "Some Alkyl Hydroxy Benzoate Preservatives (Parabens) Are Estrogenic," Toxicology and Applied Pharmacology, Vol. 153, No. 1, 1998, pp. 12-19. http://dx.doi.org/10.1006/taap.1998.8544

[11] C. Lemini, G. Silva, C. Timossi, D. Luque and A. Valverde, M. Gonzalez-Martinez, A. Hernandez, C. RubioPoo, B. C. Lara and F. Valenzuela, "Estrogenic Effects of p-Hydroxybenzoic Acid in CD1 Mice," Environmental Research, Vol. 75, No. 2, 1997, pp. 130-134. http://dx.doi.org/10.1006/enrs.1997.3782

[12] X. Ye, A. M. Bishop, L. L. Needham and A. M. Calafat, "Automated On-Line Column-Switching HPLC-MS/MS Method with Peak Focusing for Measuring Parabens, Triclosan and Other Environmental Phenols in Human Milk," Analytica Chimica Acta, Vol. 622, No. 1-2, 2008, pp. 150-156. http://dx.doi.org/10.1016/j.aca.2008.05.068

[13] G. Shanmugam, B. R. Ramaswamy, V. Radhakrishnan and H. Tao, "GC-MS Method for the Determination of Paraben Preservatives in the Human Breast Cancerous Tissue," Microchemical Journal, Vol. 96, No. 2, 2010, pp. 391-396. http://dx.doi.org/10.1016/j.microc.2010.07.005

[14] M. Ganzera, A. Aberham and H. Stuppner, "Development and Validation of an HPLC/UV/MS Method for Simultaneous Determination of 18 Preservatives in Grapefruit Seed Extract," Journal of Agricultural and Food Chemistry, Vol. 54, No. 11, 2006, pp. 3768-3772. http://dx.doi.org/10.1021/jf060543d

[15] A. Zotou, I. Sakla and P. D. Tzanavaras, "LC-Determination of Five Paraben Preservatives in Saliva and Toothpaste Samples Using UV Detection and a Short Monolithic Column," Journal of Pharmaceutical and Biomedical Analysis, Vol. 53, No. 3, 2010, pp. 785-789. http://dx.doi.org/10.1016/j.jpba.2010.05.018

[16] G. A. Shabir, "Method Development and Validation of Pereservatives Determination (Benzyl Alcohol, Ethylene Glycol Monophenyl Ether, Methyl Hydroxybenzoate, Ethyl Hydroxybenzoate, Propyl Hydroxybenzoate, and Butyl Hydroxybenzoate) using HPLC," Journal of Liquid Chromatography \& Related Technologies, Vol. 30, No. 13, 2007, pp. 1951-1962. http://dx.doi.org/10.1080/10826070701386553

[17] N. Memon, M. I. Bhanger and M. Y. Khuhawer, "Determination of Preservatives in Cosmetics and Food Samples by Micellar Liquid Chromatography," Journal of Separa- tion Science, Vol. 28, No. 7, 2005, pp. 635-638.

http://dx.doi.org/10.1002/jssc.200500060

[18] G. A. Shabir, "A New Validated HPLC Method for the Simultaneous Determination of 2-Phenoxyethanol, Methylparaben, Ethylparaben and Propylparaben in a Pharmaceutical Gel," Indian Journal of Pharmaceutical Sciences, Vol. 72, No. 4, 2010, pp. 421-425.

http://dx.doi.org/10.4103/0250-474X.73906

[19] B. R. Ramaswamy, G. Shanmugam, G. Velu, B. Rengarajan and D. G. J. Larsson, "GC-MS Analysis and Ecotoxicological Risk Assessment of Triclosan, Carbamazepine and Parabens in Indian Rivers," Journal of Hazardous Materials, Vol.186, No. 2-3, 2011, pp. 1586-1593. http://dx.doi.org/10.1016/j.jhazmat.2010.12.037

[20] L. Wang, X. Zhang, Y. Wang and W. Wang, "Simultaneous Determination of Preservatives in Soft Drinks, Yogurts and Sauces by a Novel Solid-Phase Extraction Element and Thermal Desorption-Gas Chromatography," Analytica Chimica Acta, Vol. 577, No. 1, 2006, pp. 62-67. http://dx.doi.org/10.1016/j.aca.2006.06.030

[21] T.-J. Yang, F.-J. Tsai, C.-Y. Chen, T. C.-C. Yang and M.-R. Lee, "Determination of Additives in Cosmetics by Supercritical Fluid Extraction On-Line Headspace Solidphase Microextraction Combined with Gas Chromatography-Mass Spectrometry," Analytica Chimica Acta, Vol. 668, No. 2, 2010, pp. 188-194. http://dx.doi.org/10.1016/j.aca.2010.04.001

[22] A. M. C. Ferreira, M. Moder and M. E. F. Laespada, "GC-MS Determination of Parabens, Triclosan and Methyl Triclosan in Water by in Situ Derivatisation and Stir-Bar Sorptive Extraction," Analytical and Bioanalytical Chemistry, Vol. 399, No. 2, 2011, pp. 945-953. http://dx.doi.org/10.1007/s00216-010-4339-7

[23] J. B. Claver, M. C. Valencia and L. F. Capitan-Vallvey, "Analysis of Parabens in Cosmetics by Low Pressure Liquid Chromatography with Monolithic Column and Chemiluminescent Detection," Talanta, Vol. 79, No. 2, 2009, pp. 499-506. http://dx.doi.org/10.1016/j.talanta.2009.04.012

[24] A. Myint, Q. Zhang, L. Liu and H. Cui, "Flow InjectionChemiluminescence Determination of Paraben Preservative in Food Safety," Analytica Chimica Acta, Vol. 517, No. 1-2, 2004, pp. 119-124.

http://dx.doi.org/10.1016/j.aca.2004.04.044

[25] W. Jinyan, Z. Dongli, C. Qingcui and Y. Jiannong, "Simultaneous Determination of Phenolic Additives in Cosmetics by Micellarelectrokinetic Capillary Chromatogramphy with Electrochemical Detection," Chinese Journal of Chemistry, Vol. 28, No. 2, 2010, pp. 313-319. http://dx.doi.org/10.1002/cjoc.201090073

[26] Y. Yu, Q. Huang, J. Cui, K. Zhang, C. Tang and X. Peng, "Determination of Pharmaceuticals, Steroid Hormones and Endocrine-Disrupting Personal Care Products in Sewage Sludge by Ultra-High-Performance Liquid Chromatography-Tandem Mass Spectrometry," Analytical and Bioanalytical Chemistry, Vol. 399, No. 2, pp. 891902. http://dx.doi.org/10.1007/s00216-010-4295-2

[27] T. Wu, C. Wang, X. Wang and Q. Ma, "Simultaneous Determination of 21 Preservatives in Cosmetics by Ultraperformance Liquid Chromatography," International Jour- 
nal of Cosmetic Science, Vol. 30, No. 5, 2008, pp. 367372. http://dx.doi.org/10.1111/j.1468-2494.2008.00465.x

[28] M. Mincea, I. Lupsa, I. Talpos and V. Ostafe, "UPLC Analysis of Common Parabens in Cosmetic Products," Acta Chromatographica, Vol. 21, No. 4, 2009, pp. 591-60. http://dx.doi.org/10.1556/AChrom.21.2009.4.6

[29] L. Xiu-Qin, J. Chao, Y. Wei, L. Yun, Y. Min-Li and C. Xiao-Gang, "UPLC-PDAD Analysis of Simultaneous Determination of Ten Synthetic Preservatives in Foodstuff," Chromatographia, Vol. 68, No. 1-2, 2008, pp. 57-63. http://dx.doi.org/10.1365/s10337-008-0645-Z

[30] J. G. Jimenez, M. C. Valencia and L. F. Capitan-Vallvey, "Parabens determination with a hybrid FIA/HPLC system with ultra-short monolithic column," Journal of Analytical Chemistry, Vol. 65, No. 2, 2010, pp. 188-194. http://dx.doi.org/10.1134/S1061934810020152

[31] S. Dalibor, S. Petr, C. Petr and K. Rolf, "Monolithic columns-a new concept of separation in the sequential injection technique," Analytica Chimica Acta, Vol. 499, No. 10, 2003, pp. 205-214.

[32] L.-P. Labranche, A. Tousignant, D. Abran and A. Carrier, "Fast Determination of 4-Hydroxybenzoic Acid in Different Matrices Using Monolithic Column Separation,"
Journal of Liquid Chromatography \& Related Technology, Vol. 31, No.17, 2008, pp. 2575-2586. http://dx.doi.org/10.1080/10826070802352777

[33] S. H. Kang and H. Kim, "Simultaneous Determination of Methylparaben, Propylparaben and Thimerosal by HighPerformance Liquid Chromatography and Electrochemical Detection," Journal of Pharmaceutical and Biomedical Analysis, Vol. 15, No. 9-10, 1997, pp. 1359-1364. http://dx.doi.org/10.1016/S0731-7085(96)02031-6

[34] I. Martins, F. C. Carreira, L. S. Canaes, F. A. S. C. Campos, L. M. S. Cruz and S. Rath, "Determination of parabens in shampoo using high performance liquid chromatography with amperometric detection on a boron-doped diamond electrode," Talanta, Vol. 85, No. 1, 2011, pp. 17. http://dx.doi.org/10.1016/j.talanta.2011.04.047

[35] L. S. Andrade, M. C. Moraes, R. C. Rocha-Filho, O. Fatibello-Filho and Q. B. Cass, "A Multidimensional High Performance Liquid Chromatography Method Coupled with Amperometric Detection Using a Boron-Doped Diamond Electrode for the Simultaneous Determination of Sulfamethoxazole and Trimethoprim in Bovine Milk," Analytica Chimica Acta, Vol. 654, No. 2, 2009, pp. 127132. http://dx.doi.org/10.1016/j.aca.2009.09.035 